\title{
Influence of Different Connecting Rod Configurations on the Stability of the Ilizarov/TSF Frame: A Biomechanical Study
}

\author{
Gerhard Thiart ${ }^{1}$, Christopher Herbert ${ }^{2}$, Sudesh Sivarasu ${ }^{3}$, Saadiq Gasant ${ }^{4}$, Maritz Laubscher ${ }^{5}$
}

\begin{abstract}
Aim: The llizarov external fixator (IEF) is frequently used in trauma and elective orthopaedics. Many of its biomechanical variables (ring size, wire diameter, wire number, half pins vs wires, etc.) and their influence on stability and stiffness have been investigated. There is, however, a paucity in the literature regarding the influence of the connecting rod numbers and configurations between the rings on IEF stability. The primary aim of this biomechanical study was to compare the stability between four- and three-rod IEF configurations. Secondarily to assess the difference in stability between symmetrical and asymmetrical spacing of the IEF rods.

Materials and methods: A custom jig was designed to facilitate mounting of a basic two-ring IEF in a hydraulic press. Controlled centre and off-centre (thus simulated bending) axial loading was then applied across the frame. The configurations were loaded up to 4,000 N. The frame deformation was plotted and the data were then analysed and interpreted.

Results: Negligible differences were observed between different four- and three-rod configurations as long as the applied force at the loading point (LP) was within the area of support (AOS) created by the rods. The different four-rod constructs were always more stable than the threerod constructs during bending.

Conclusion: There is comparable stiffness between a four-rod and a three-rod IEF construct as long as the LP is within the AOS created by the rods. A four-rod IEF is stiffer than a three-rod IEF in bending.

Clinical significance: This study will possibly change some paradigms regarding the planning and application of IEFs by Orthopaedics Traumatologists and Reconstruction Surgeons.

Keywords: Connecting rod, Ilizarov technique, Stability, Stiffness.

Strategies in Trauma and Limb Reconstruction (2020): 10.5005/jp-journals-10080-1447
\end{abstract}

\section{InTRODUCTION}

Professor Gavriil Abramovich Ilizarov developed his Ilizarov external fixator (IEF) during the 1950s. It was only presented to Western Medicine via Italy in 1981 and subsequently become an indispensable trauma and elective surgical tool.

A high volume of research has been and still is being conducted on the different mechanical aspects of the llizarov frame. Most are in vitro studies and of a biomechanical nature. The fine wires were investigated for material type, wire type, thickness, pretension, number, planes, and angles of convergence. ${ }^{1-10}$ The effects of half pins were investigated ${ }^{11-13}$ as well as the wire fixation bolt holding mechanism. ${ }^{1,14,15}$ The rings were studied in regard to material type, size/diameter, design, number used, configuration as well as position in relation to the bone segment. ${ }^{5,7,12,13,16-19}$ Also, the influence of the fracture configuration on frame stability has been studied. ${ }^{3,17}$ The last component to comment on was the connecting rods that hold the rings in a fixed relationship to each other, which is parallel and fixed in spanning distance.

Classically, it was described by llizarov to use four connecting rods, symmetrically spaced, between adjacent rings and most authors will attest to this view. ${ }^{9,18-20}$ Some situations may force a clinician to use only three rods or space the rods asymmetrically around the frame circumference. This may be to allow access to the limb for a plastic surgeon or if the ring circumference is too small to allow four rods and enough fixation points as with paediatric sized rings.
${ }^{1}$ Department of Orthopaedics, Worcester Provincial Hospital, Worcester, Western Cape, South Africa; Department of Orthopaedic Research, Groote Schuur Hospital Unit, University of Cape Town, Cape Town, Western Cape, South Africa

${ }^{2-4}$ Department of Biomechanical Engineering, University of Cape Town, Cape Town, Western Cape, South Africa

${ }^{5}$ Department of Orthopaedic Research, Groote Schuur Hospital Unit, University of Cape Town, Cape Town, Western Cape, South Africa

Corresponding Author: Gerhard Thiart, Department of Orthopaedics, Worcester Provincial Hospital, Worcester, Western Cape, South Africa; Department of Orthopaedic Research, Groote Schuur Hospital Unit, University of Cape Town, Cape Town, Western Cape, South Africa, Phone: +27 845252177, e-mail: dr.gerhard.thiart@gmail.com

How to cite this article: Thiart G, Herbert C, Sivarasu S, et al. Influence of Different Connecting Rod Configurations on the Stability of the Ilizarov/TSF Frame: A Biomechanical Study. Strategies Trauma Limb Reconstr 2020;15(1):23-27.

Source of support: South African Orthopaedic Association (SAOA) Conflict of interest: None

The number of rods (four or more), rod thickness, and rod angle has been investigated. ${ }^{18,19}$ No research could be found pertaining to the use of four rods vs three as well as to different spacing positions of the rods around the circumference of the IEF rings and its influence on frame stability. At least nothing is available in the published English medical literature.

() The Author(s). 2020 Open Access This article is distributed under the terms of the Creative Commons Attribution 4.0 International License (https://creativecommons. org/licenses/by-nc/4.0/), which permits unrestricted use, distribution, and non-commercial reproduction in any medium, provided you give appropriate credit to the original author(s) and the source, provide a link to the Creative Commons license, and indicate if changes were made. The Creative Commons Public Domain Dedication waiver (http://creativecommons.org/publicdomain/zero/1.0/) applies to the data made available in this article, unless otherwise stated. 
The primary question we want answered was if there was any difference in stability between four- and three-rod IEF configurations. Secondarily if there was any difference in stability between symmetrically and asymmetrically spaced rod IEF configurations.

\section{Materials and Methods}

Two 155-mm Taylor Spatial Frame ${ }^{\text {TM }}$ (TSF) (Smith and Nephew, Memphis, USA) full rings were used to construct 10 basic frame configurations consisting of 2 rings only. The configurations were divided into two groups. The first group (Group Square - S\#) all were constructed using four rods and had five different constructs (S1-5). The second group (Group Triangle - T\#), using three rods, also had five different constructs $(\mathrm{T} 1-5)$. The groups were pairable in design, e.g., S1/T1, S2/T2, S3/T3, S4/T4, and S5/T5 (Fig. 1). The rods were of 6-mm threaded medical grade stainless steel (Smith and Nephew, Memphis, USA). The distance between the rings was fixed at $15 \mathrm{~cm}$. The first test sample in each group ( $\mathrm{S} 1$ and $\mathrm{T} 1$ ) was constructed with the rods equally spaced around the circumference of the rings. Thus, S1's rod placement was every $90^{\circ}$ and T1's rod placement every $120^{\circ}$. Then, subsequent configurations in each group had the anteriorly placed two rods be moved wider and wider apart. The posterior two rods in the square group were moved proportionately closer. In the triangle group, the third rod, making up the triangle, was always positioned at the most posterior point on the ring. Thus, the apex of the triangle was always posterior in the anterior-posterior (AP) plane. Test samples S3 and T3 both had
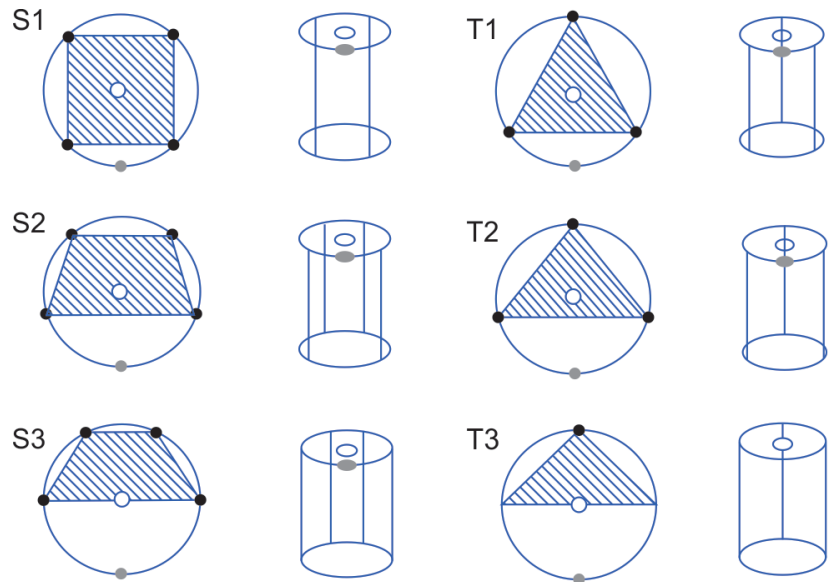

T3
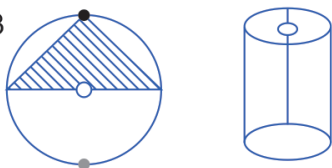

S4
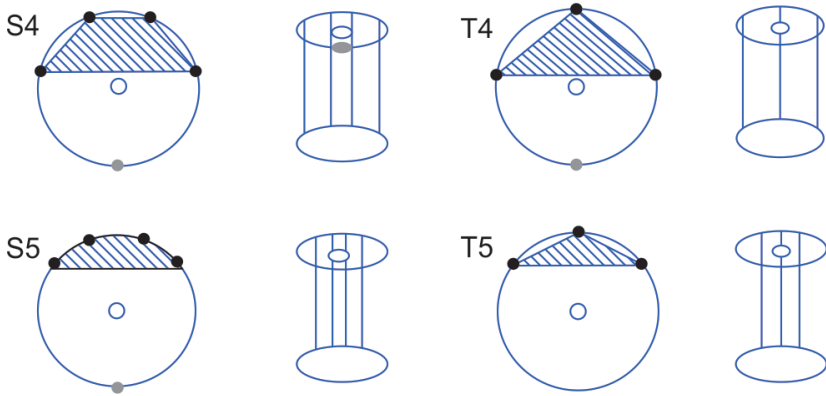

Fig. 1: Two paired test groups consisting of four- (Square - S\#) and three- (Triangle - T\#) rod configurations. The solid black dots represent rod positions on the rings. The greyed out area represents the area of support (AOS) formed between the rods. The black circle represents the centre loading point (LP). The grey circle represents the off-centre LP the anterior two rods positioned on the ring equator with spacing in-between of $180^{\circ}$.

The frames were then loaded into a Zwick 1484 Universal Testing Machine. A custom-made jig was developed for this study, so that the frames could be securely mounted in the Zwick machine. All the frames were then axially loaded at $1 \mathrm{~mm} /$ minute up to $4000 \mathrm{~N}$ (Fig. 2). Previous studies used upper loading values of 700 $\mathrm{N}$, far less than what was applied here, due to that representing the downward force of a standing man of average weight. ${ }^{19} \mathrm{We}$ argued that during normal gait up to 4.45 times body weight could pass through the lower third tibia. ${ }^{21}$ Also, a high percentage South Africans are generally obese, with more than $50 \%$ of men and more than $60 \%$ of women being overweight in $2008 .^{22}$ During the centrally directed axial loading tests, all five test samples of each group (S1-5 and T1-5) were tested. During the off-centre (simulated bending) axial loading test, the last test sample of each group (S5 and T5, respectively) was not tested due to test samples S4 and T4 already demonstrating severe instability (bending). Bending was only tested in the AP plane, and on the anterior aspect of the ring, as this was the area of interest. This was the area where the anterior two struts were being moved incrementally further apart and thus where the frame would theoretically have increasingly less support and stability. Torsional stress was not tested as we were unable to attain a modification of the custom jig that would convert an axially directed force into a coupled torsional directed force (as was performed by Podolsky and $\mathrm{Chao}^{7}$ ).

We did not use a biological model due to the complexity of recreating a representative model of the in vivo tibia. We felt that any attempt would not be representative and introduce unnecessary variables.

The first and second authors constructed all the frames, using the standard llizarov set tools, performed all the tests, after being trained by the Engineering department, and analysed the data. Each test was performed only once. Frame deformation, seen as shortening of the set $15 \mathrm{~cm}$ between the two rings, was electronically captured by the Zwick machine. The results were plotted by testXpert ${ }^{\mathrm{IT}}{ }^{\mathrm{TM}}$ software. The results were then further analysed in Microsoft Office Excel $365^{\mathrm{TM}}$. Descriptive statistics were used to describe the data and no further statistical analysis was performed after discussion with a statistician.

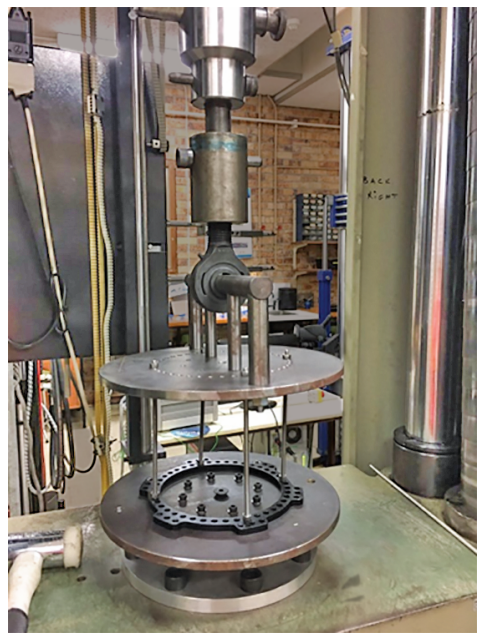

Fig. 2: A four-rod test sample mounted in the custom jig before testing in the Zwick 1484 Universal Testing Machine 


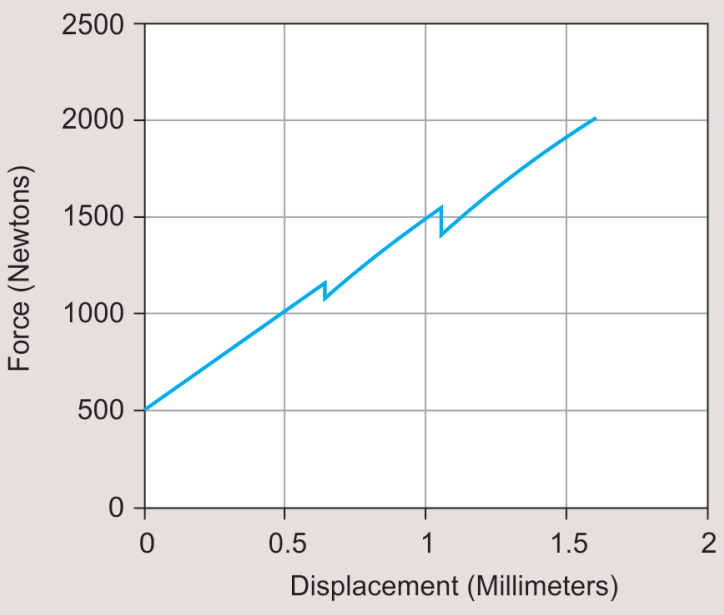

Fig. 3: A graph depicts the sudden decreases in load as the rods shift in the ring holes

\section{Results}

The initial parts of the load-deformation curves varied in no consistent pattern between the different frames. This was seen between the values of 0 and $500 \mathrm{~N}$. We realised that this was due to the different contact points between the Zwick machine, the custom jig, and the frame components "settling in" as the initial loading pressure was being applied. Afterward, the curves started to show a smooth trend which made interpretation possible.

In some of the samples at the extreme of testing (Fig. 3), we noticed a sudden dip in the load-displacement curve which was attributed to the rods, being held in the TSF ring rod hole by nuts on both sides, shifting. It is well known that the holes in the classic Ilizarov and the TSF rings' diameter are wider than the $6 \mathrm{~mm}$ rods. After the rod settled in a firmer position on the side of the hole, the curve quickly returned to its normal overall trend.

After eliminating the initial parts of the curves between 0 and $500 \mathrm{~N}$, we zeroed all the curves to start from the same point on the chart, so that comparison between test samples could be made.

\section{Centrally Applied Axial Force}

Like the study performed by Tan et al.., ${ }^{19}$ we also demonstrated that all the frames are more stiff during centrally applied loading than off-centred loading (simulating a bending moment). Paired samples S1/T1, S2/T2, and S3/T3 displayed similar load-bending curves (Fig.4). There was no significant observed difference between them and their stability did not seem to weaken in a specific logical order. There was overlap at different places between the curves of S1, T1, S2, and T2. S3 and T3 did display less stiffness but this was only really apparent nearing forces more than $3,000 \mathrm{~N}$. What was very apparent was the reduction in stiffness displayed by test samples S4/T4 and even more so by S5/T5. This instability is due to the distance between the anterior two rods being more than $180^{\circ}$. All the rods were thus posterior to the ring equator and to the centrally applied axial force loading point (LP). The applied force was thus acting as a bending moment.

\section{Off-centre Applied Axial Force}

In these tests, the difference between the two test groups became more apparent. All the constructs showed increasing less resistance to bending in a logical ordinal manner (Fig. 5). S1/T1 were the stiffest,

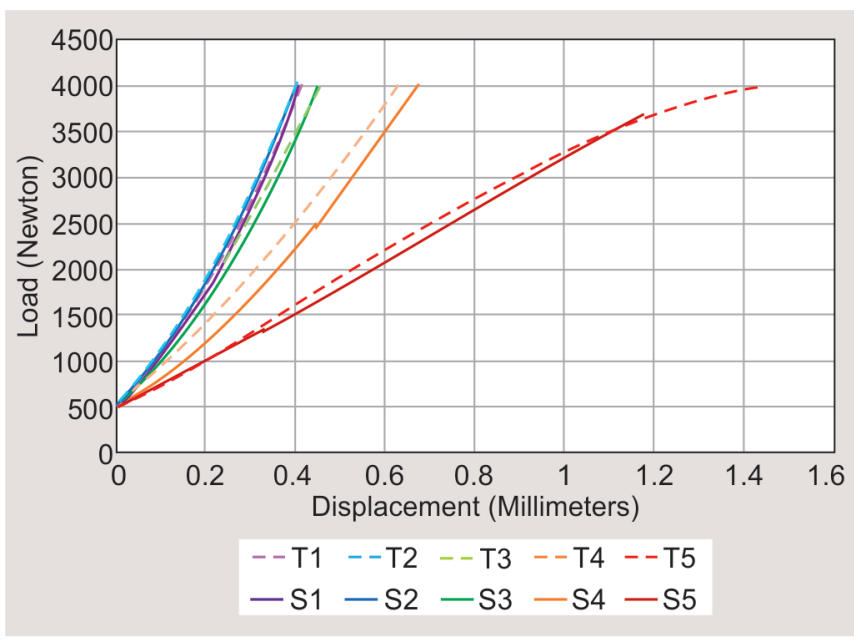

Fig. 4: The load-displacement curves during centre axial loading

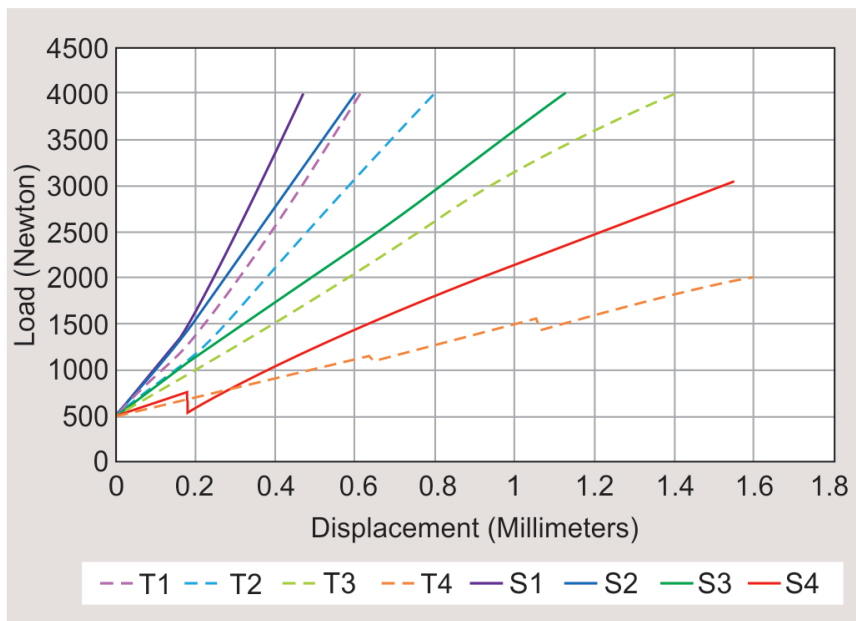

Fig. 5: The load-displacement curves during off-centre axial loading (simulated bending)

followed by S2/T2, then S3/T3 and finally S4/T4 being the weakest (to such a degree that the S5/T5 bending tests were abandoned). In the paired groups, the four-rod test sample was always stiffer in comparison to its three-rod counterpart.

\section{Discussion}

It has been well demonstrated using Perren's strain theory ${ }^{23}$ that bone healing was influenced by axial force vectors. ${ }^{24-26}$ The beneficial as well as detrimental effects of axial force and frequency (compressive and distractive) have been well investigated, even though there is uncertainty to which one is best. ${ }^{27}$ The other force vectors (bending, translational, and torsional) are still considered to be detrimental to bone healing, ${ }^{5,28}$ even though some authors found evidence contradicting this. ${ }^{29}$ Due to this current understanding of force vectors on bone healing, the priorities of any fixation device (be that either internal or external) are to neutralise any bending, translational, and rotational shear forces while at the same time controlling axial forces within the boundaries of the device's design and application purpose. On the one hand for direct healing, absolute stability (torsional, translational, and 
bending all neutralised) with compression across the fracture gap is required. On the other hand for indirect healing torsion, translation as well as bending must be neutralised but axial forces have to be controlled within the tolerable stress range of the tissue that needs to form. The IEF also needs to deliver on these requirements.

The various IEF components, and each's influence on the different force vectors, have been extensively studied, except for the connecting rod configurations. It is assumed from Ilizarov's original work that four connecting rods, as near to symmetrically spaced around the circumference of the rings, are the standard of care. Numerous authors attest to this view of using four rods. ${ }^{9,18-20}$ Only Podolsky and Chao mentioned three rods may be used, although it did not form part of his investigation. ${ }^{7}$ Even though some studies have looked at an increased number of rods (more than four), ${ }^{19}$ none investigated the use of three. Some clinicians prefer the use of three rods as this reduces the complexity of the frame. Also, none of the studies looked at asymmetrical spacing of the rods. This is very much the case in clinical practice, as the rods may need to be moved out of a position of symmetry to account for a wire or half pin that needs to be put in that very position on the ring. This also is the case when an ankle spanning frame is applied. A full ring on the distal tibia needs to be connected to a U-ring around the foot. Symmetrical spacing around the distal tibia is impossible as the full and U-rings do not match up in shape.

After comparing the different test samples, a few observations could be made by looking at the load-displacement curves.

There seems to be no significant difference between the stability, during central axial loading, of the four- and three-rod test samples as long as the LP falls within the area of support (AOS) created between the rods (refer to the schematic of test samples $\mathrm{S} 1 / \mathrm{T} 1$ and $\mathrm{S} 2 / \mathrm{T} 2$ in Fig. 1). This observation is also applicable if the LP falls on the border of the AOS (refer to the schematic of test sample S3/T4 in Fig. 1). Once the LP falls outside the AOS, the same centrally applied force becomes a bending moment and the frame starts to deform. The resulting effect being that the anterior part of the frame is being compressed while the posterior part is being distracted. This rate of deformation becomes more pronounced the further outside the AOS the LP falls. If the bone segment is seen as the axis of the LP, then to be sure that the LP is within the AOS there has to be a visible rod on each side of the bone segment on both the AP and lateral views. The "rule of twos", as described by Rozbruch and llizarov, is a well-known guide to IEF construction: ${ }^{20}$

- $2 \mathrm{~cm}$ between skin and frame.

- 2 rings per bone segment.

- 2 point of fixation per ring.

- $2 \times 2$ (thus 4) connecting rods between rings.

- Both ends (thus 2) of the bone segment must be stabilised - the "near and far" principle.

- 2 planes of fixation per ring.

Due to the test findings, it could be considered adding to the rules "rods on 2 sides on 2 views (one on either side of the bone segment)". This would be most relevant in the tibia where the bone is eccentrically placed within the lower leg and the rings. Care should be taken to keep the tibia within the AOS of the frame.

The off centre axially applied (simulated bending) tests gave more insight into the difference in stability between the four- and three-rod test samples. Between the different test pairs, S1/T1, S2/ $\mathrm{T} 2, \mathrm{~S} 3 / \mathrm{T} 3$, and S4/T4, the four-rod test sample was always more resistant than the three-rod test sample to bending. Since the LP was outside the AOS from the onset the load-displacement curves were worse than for the corresponding centrally loaded test pair. The reason for the square four-rod test samples being more resistant to bending was likely due to the two posterior rods that provided more rigidity than the single posterior rod of the triangular threerod test samples.

All the test samples had a curved load-displacement graph. Even the test samples loaded centrally with the LP falling within the AOS. This means that with any frame, even sturdily built, following correct placement principles of all the components as described by the literature, that there will be a very minor shortening of the distance between the rings spanning the fracture site on each step. This indicates that the rods have to be bulging sideward, within its elastic capacity, during the weight-bearing phase of the gait cycle. Does this actually happen in vivo? Maybe not as the smooth wire and half pins are likely absorbing the axial force. Since this study did not apply the axial forces through a bone-wire interface, we can only speculate.

\section{Study Limitations}

There are limitations to our study, foremost it being an in vitro study. Manipulating only one isolated variable in a biomechanical study will never be a proper substitute for a randomised control clinical trial. But it is still a good and safe departure point for further research. Also, we did not test posterior, lateral, or medial bending. Rotational stability was also not assessed. Critique may also be levered at the manipulation of the data to make the loaddisplacement graphs overlap and thus be more comparable. Since it was never the aim of the study to gather absolute values for stiffness but rather to compare trends this may well be considered a minor weakness. Another limitation was that only a single ring size $(160 \mathrm{~mm})$ was used during testing. With smaller ring sizes (e.g., $80 \mathrm{~mm}$ ), the construct's stiffness may be so high that the spacing of the rods may be irrelevant.

\section{Future Research}

Future investigation may further exploit the LP in the AOS, the "rods on 2 sides on 2 views", principle. By constructing further test samples with asymmetrically spaced rods, the LP could be shifted to always stay within the AOS and see if the load-displacement curves' trend changes. Torsional stiffness also needs to be investigated between different rod configurations. The same concept may also be tested with a biological model, with a standardised wire or half pin configuration (to remove confounding factors) to see if the bone segment can be substituted for the LP.

\section{CONCLUSION}

There is comparable stiffness between a four- and a three-rod IEF during axial load as long as the LP remains within the AOS (formed by the rods). A four-rod IEF is stiffer in bending than a three-rod IEF. Recommendations regarding the use of a three-rod construct, if unavoidable, cannot be supported or refuted by this research.

\section{Clinical Significance}

Some elements or techniques regarding the applications of IEFs are sometimes very dogmatic and the origin of some of the "seen as standard" principles are never explored. This study aims to explore one of these application principles and possibly the results will 
change the paradigm of some Orthopaedic Traumatologists and Reconstructive Surgeons.

\section{ACKNOWLedgments}

This study would not have been possible if not for the custom jig designed by Mr Christopher Herbert as well as the help of $\mathrm{Mr}$ Sudesh Sivarasu, both working in the Biomedical Engineering Department of UCT. Also, we need to thank Ms Penny Louw at the UCT Engineering department for the training in and use of the Zwick machine. I hereby thank Dr Maritz Laubscher, my supervisor, for the help and guidance with this study. Lastly, I thank my wife and children for always being there with me during my registrar time. This article does not contain any studies with human or animal participants performed by any of the authors.

\section{Patient Consent Forms}

Not applicable as this was as biomechanical study not involving any human or animal tissue.

\section{References}

1. Aronson J, Harp Jr JH. Mechanical considerations in using tensioned wires in a transosseous external fixation system. Clin Orthop Relat Res 1992;280(280):23-29. DOI: 10.1097/00003086-199207000-00005.

2. Caja VL, Kim W, Larsson S, et al. Comparison of the mechanical performance of three types of external fixators: linear, circular and hybrid. Clini Biomechan 1995;10(8):401-406. DOI: 10.1016/02680033(95)00014-3.

3. Calhoun JH, Li F, Ledbetter BR, et al. Biomechanics of the llizarov fixator for fracture fixation. Clin Orthop Relat Res 1992;280(280):15-22. DOI: 10.1097/00003086-199207000-00004.

4. Davidson A, Mullins M, Goodier D, et al. Ilizarov wire tensioning and holding methods: a biomechanical study. Injury 2003;34(2):151-154. DOI: 10.1016/s0020-1383(02)00045-1.

5. Fleming B, Paley D, Kristiansen T, et al. A biomechanical analysis of the Ilizarov external fixator. Clin Orthop Relat Res 1989;241(241):95-105. DOI: 10.1097/00003086-198904000-00012.

6. La Russa V, Skallerud B, Klaksvik J, et al. Reduction in wire tension caused by dynamic loading. An experimental llizarov frame study. J Biomech 2011;44(8):1454-1458. DOI: 10.1016/j.jbiomech.2011.03.018.

7. Podolsky A, Chao EY. Mechanical performance of llizarov circular external fixators in comparison with other external fixators. Clin Orthop Relat Res 1993;293(293):61-70. DOI: 10.1097/00003086199308000-00009.

8. Roberts CS, Antoci V, Voor MJ. The effect of transfixion wire crossing angle on the stiffness of fine wire external fixation: a biomechanical study. Injury 2005;36(9):1107-1112. DOI: 10.1016/j.injury.2004.08.018.

9. Spiegelberg B, Parratt T, Dheerendra S, et al. Ilizarov principles of deformity correction. Ann Royal Coll Surg Engl 2010;92(2):101-105. DOI: 10.1308/003588410X12518836439326.

10. Zhang G. Avoiding the material nonlinearity in an external fixation device. Clinical Biomechanics 2004;19(7):746-750. DOI: 10.1016/ j.clinbiomech.2004.04.001.

11. Calhoun J, Li F, Bauford W, et al. Rigidity of half-pins for the llizarov external fixator. Bulletin (Hospital for Joint Diseases (New York, NY)) 1991;52(1):21-26.
12. Duda G, Kassi J-P, Hoffmann J, et al. Mechanisches verhalten von ilizarov-ringfixateuren einfluss der gestaltparameter auf die steifigkeit und konsequenzen für den klinischen einsatz. Unfallchirurg 2000;103(10):839-845. DOI: 10.1007/s001130050630.

13. Sarpel $Y$, Gulsen $M$, Togrul E, et al. Comparison of mechanical performance among different frame configurations of the llizarov external fixator: experimental study. J Trauma: Inj, Infect Crit Care 2005;58(3):546-552. DOI: 10.1097/01.ta.0000152550.48706.a7.

14. Gessmann J, Jettkant B, Königshausen M, et al. Improved wire stiffness with modified connection bolts in ilizarov external frames: a biomechanical study. Acta Bioeng Biomech 2012;14(4):15-21.

15. Mullins $M$, Davidson $A$, Goodier $D$, et al. The biomechanics of wire fixation in the llizarov system. Injury 2003;34(2):155-157. DOI: 10.1016/ s0020-1383(02)00262-0.

16. Bronson DG, Samchukov ML, Birch JG, et al. Stability of external circular fixation: a multi-variable biomechanical analysis. Clin Biomechans 1998;13(6):441-448. DOI: 10.1016/s0268-0033(98) 00007-2.

17. Cross AR, Lewis DD, Murphy ST, et al. Effects of ring diameter and wire tension on the axial biomechanics of four-ring circular external skeletal fixator constructs. Am J Vet Res 2001;62(7):1025-1030. DOI: 10.2460/ajvr.2001.62.1025.

18. Fragomen AT, Rozbruch SR. The mechanics of external fixation. HSS J 2007;3(1):13-29. DOI: 10.1007/s11420-006-9025-0.

19. Tan B, Shanmugam R, Gunalan R, et al. A biomechanical comparison between Taylor's spatial frame and Ilizarov external fixator. Malays Orthop J 2014;8(2):35-39. DOI: 10.5704/MOJ.1407.012.

20. Rozbruch SR, llizarov S. Limb lengthening and reconstruction surgery. CRC Press; 2006.

21. Voinescu M, Soares D, Castro M, et al., A study of moments acting on the tibia during gait in the active elderly population. In: ISBSConference Proceedings Archive, 2011. vol 1.

22. Morris AG. Fatter and fatter: South Africa's rise in body mass index. S Afr J Sci 2011;107(3-4):01-01. DOI: 10.4102/sajs.v107i3/4.650.

23. Perren S. Physical and biological aspects of fracture healing with special reference to internal fixation. Clin Orthop Relat Res 1979;138(138):175-196.

24. Claes LE, Heigele CA, Neidlinger-Wilke C, et al. Effects of mechanical factors on the fracture healing process. Clin Orthop Relat Res 1998;355(355 Suppl):S132-S147. DOI: 10.1097/00003086-19981000100015.

25. Goodship A, Kenwright J. The influence of induced micromovement upon the healing of experimental tibial fractures. Bone \& Joint Journal 1985;67(4):650-655. DOI: 10.1302/0301-620X.67B4.4030869.

26. Goodship AE, Cunningham JL, Kenwright J. Strain rate and timing of stimulation in mechanical modulation of fracture healing. Clin Orthop Relat Res 1998;355(355 Suppl):S105-S115. DOI: 10.1097/00003086199810001-00012.

27. Jagodzinski $M$, Krettek $C$. Effect of mechanical stability on fracture healing —an update. Injury 2007;38(1):S3-S10. DOI: 10.1016/ j.injury.2007.02.005.

28. Harwood PJ, Newman JB, Michael ALR. (ii) An update on fracture healing and non-union. Orthopaedics and Trauma 2010;24(1):9-23. doi: 10.1016/j.mporth.2009.12.004.

29. Park S-H, O'Connor K, McKellop H, et al. The influence of active shear or compressive motion on fracture-healing. J Bone Joint Surg Am 1998;80(6):868-878. DOI: 10.2106/00004623-19980600000011. 